\title{
International Year of the Nurse
}

\section{Jussara Gue Martini}

Scientific Editor of REBEn and Director of Publications and Social Communication of ABEn (2007-2010)

In the year 2010, declared the International Year of the Nurse in collaboration with other organizations in the world, nurses seek to demonstrate how to intercede and act globally, to build a healthy world, with a commitment to bring health to families and communities, locally or globally.

By the time the nurses sign the "Nightingale Declaration for a Healthy World" (for signing visit: http:// www.nightingaledeclaration.net/), supporting the worldwide celebration of the International Year of the Nurse and the Centenary of Florence Nightingale, in Brazil we face resistance from legislative approval of the Federal Law of 30 hours per week, being processed for more than a decade.

The arguments that the Brazilian nursing has used to support the adoption of the Law were, once again, highlighted in a research developed at the Laboratory for Education in Environment and Health Department of Biology of the Instituto Oswaldo Cruz (IOC/FIOCRUZ), under the guidance of Lucia Rotemberg and William Waissmann, by the biologist Luciana Fernandes Portela. The master's dissertation in public health "Morbidity referred to in professional nursing: relations with timetable work, weekly work and housework", involving 280 nursing staff of two hospitals in Rio de laneiro (including 20 men and 260 women) were considered as factors that affect the health professionals, working hours more than 40 hours weekly and the interactions between work professional and domestic, in addition to the nighttime work hours and high charge of activities.

Studies like this move us and reinforce our commitment to nurses worldwide struggle for health, also for the category.

The REBEn, in attention to their goals presents in this issue, research, reviews and experience reports that address knowledge in the areas of women's health, education, child health, adult health, among others. The study of mothers with HIV/AIDS, demand discussion for the dilemmas and conflicts of pregnancy for these women, women's health is addressed also through critical analysis of the information system about prenatal care from a city in São Paulo State, a reflection on the legal responsibilities of the nurse in obstetrics and from the perspective of myths and scientific findings about the influence of lunar cycles in delivery.

In education, the reader will find information on the analysis of the formation of masters in nursing, in Santa Catarina, in the look of the post graduates, a comprehensive care as educational competence of the nurse, health education from the cultural circles, the incorporation of theoretical and methodological assumptions in Paulo Freire in research and the evaluation in clerkships in nursing administration, in a dialectical perspective.

The attention to children's health is examined from the point of view of the support network for families of children in pediatric intensive care units and the trends of perinatal mortality in Belo Horizonte. The social representations of the body of diabetics, physical activity of teenagers, as the liaison nurse as a strategy for network integration and new diagnoses of nursing in imaging, submitted to NANDA International, as well as investigations in surgical center and in central and sterilization of material, are other issues addressed by the authors in the articles of this issue.

Reiterating the invitation to sign the Nightingale Declaration for a Healthy World, we wish you a good read. 